\title{
Review of recent literature on microneedle vaccine delivery technologies
}

\author{
This article was published in the following Dove Press journal: \\ Vaccine: Development and Therapy \\ 2I August 2013 \\ Number of times this article has been viewed
}

\section{Anto Vrdoljak}

Development Laboratory, Genera, Rakov Potok, Croatia
Correspondence: Anto Vrdoljak

Development Laboratory, Biology

Division, Genera, 2 Svetonedeljska,

Kalinovica, Rakov Potok 10436,

Croatia

Tel +385 I 3388635

Email anto.vrdoljak@genera.hr

\begin{abstract}
Microneedles (MNs) have been developed as medical devices for enhanced and painless transdermal drug and vaccine delivery. MN-based vaccine application, unlike conventional intramuscular or subcutaneous application using hypodermic needles, delivers vaccine directly into skin, which is known to be an immunologically much more relevant vaccination site than underlying tissue. Vaccination using MN devices targets the skin's rich immune system, leading to better utilization of the antigen and resulting in superior immune response, often achieved using a lower vaccine dose than required by conventional delivery routes. However, despite the number of advantages and nearly four decades of research, the number of licensed MN-based vaccines remains limited to date. Nevertheless, it is to be expected that on the back of a number of recently developed scalable and robust $\mathrm{MN}$-fabrication methods, more intensive translation into clinical practice will follow. Here, we review the current status and trends in research of MN-related vaccine delivery platforms, focusing on the most promising approaches and clinically relevant applications.
\end{abstract}

Keywords: microneedles, vaccine delivery, skin vaccination

\section{Introduction}

Most current human vaccines are still delivered using a hypodermic needle. With a few rare exceptions, such as oral polio vaccine or intranasal influenza vaccine, traditional intramuscular or subcutaneous injection is still the preferred route of application, even for novel vaccines. This is not due to a lack of alternative approaches - quite the contrary. A number of alternative needle-free vaccine delivery platforms have been suggested over the past few decades. ${ }^{1}$ The long list includes edible vaccines, ${ }^{2}$ various physical methods for delivery of DNA-based vaccines (gene gun, electroporation, ultrasound ${ }^{1,3,4}$, high-velocity powder and liquid-jet injection, ${ }^{5,6}$ diffusion-based patches combined with skin abrasion/ablation ${ }^{7-9}$ and chemical enhancers, ${ }^{10}$ microneedles (MNs), ${ }^{11}$ and others. ${ }^{12}$ Many of these platforms are at least partially complementary in their potential applications. The choice of the optimal delivery method largely depends on the nature of the vaccine (protein, DNA, virus, etc), nature of the adjuvant, and formulation details. To date, the most commercially successful have been devices compatible with existing liquid or lyophilized formulations based on liquid-jet and microinjection/microneedle technologies. ${ }^{13}$ Use of MN-based technologies for vaccine delivery has been attracting considerable interest lately, driven by both increasing knowledge of skin immunology and advances in microelectronics, which enable production of such micron-scale devices. The concept of submillimeter needle-shaped structures that would pierce through the outermost skin layers and increase their 
permeability several thousandfold but without stimulating the underlying nerve endings and causing pain was first conceptualized in 1976. ${ }^{14}$ Early development of MNs was focused mainly on delivery of low-dose, low-molecularweight drugs into the skin. In the last decade, the use of MNs as a vaccine delivery platform has gained significant interest, driven largely by recent efforts to develop novel, painless, and dose-sparing influenza vaccines. ${ }^{11,15}$

$\mathrm{MN}$-assisted vaccine delivery has the potential to overcome many of the disadvantages of traditional needleand-syringe delivery routes. Injections using hypodermic needles are invasive and painful, the vaccine delivered may have a less than ideal pharmacokinetic profile, ${ }^{16}$ and result in intentional reuse and unintentional needle injuries, which may be responsible for over a half million deaths annually due to transmission of infectious diseases. ${ }^{17} \mathrm{MN}$-based vaccine platforms may deliver the vaccine dose reproducibly, enhance the pharmacokinetic profile, improve the safety of the application, decrease the level of expertise needed for application, and eliminate the risks and costs of sharps waste disposal. In addition, there is a reasonable potential that for certain types of vaccines, the dose needed for effective immunization using MNs may be significantly lower than if delivered via conventional application routes. Intramuscular and to some extent intradermal injection of vaccine bypasses the upper layers of skin and the skin's immune system and delivers the vaccine into the immunologically less relevant areas, such as muscle and subcutaneous tissue. The skin, in contrast, is exceptionally rich in dermal dendritic cells and epidermal Langerhans cells, and provides efficient drainage to lymph nodes, thus making it a much more attractive site for vaccination. ${ }^{18,19}$ Such improved utilization and better pharmacokinetic profile of antigen(s) delivered may result in dose-sparing, which may be especially relevant in the case of urgent need of a large quantity of vaccines, eg, in the case of unexpected pandemics. ${ }^{20-26}$

\section{Vaccine delivery using microneedles: current status}

Use of MN-based platforms for vaccination has been extensively studied using a large number of model antigens and clinically relevant vaccines (Table 1). To date, by far the most studied have been possibilities for using MN platforms for influenza vaccination. This is more a reflection of the general focus of global vaccine research in recent years rather than the particular suitability of influenza vaccines for $\mathrm{MN}$ delivery compared with other pathogens.

Most studies were animal models, and very few human trials reports are available. ${ }^{45,48-51}$ It is generally accepted that major immunological findings obtained using appropriate animal models can in their essence be extrapolated to the expected results of future human studies. ${ }^{92,93}$ However, certain results derived from animal studies of MNs have to be evaluated keeping in mind differences in the structure and elasticity of animal versus human skin. For example, mouse skin is known to be more elastic than human skin, making it more resistant to $\mathrm{MN}$ penetration. ${ }^{43}$ If applicable, perhaps the best laboratory model for MN research is the use of human cadaver skin, ${ }^{39,67}$ albeit availability and regulatory requirements may dissuade one from this approach.

Despite outstanding research-and-development efforts, most of the $\mathrm{MN}$-vaccine projects are still in the proof-ofconcept stage, with only a few pursued into clinical stages and even fewer resulting in licensed MN-based vaccines. This is partly due to the fact that a great amount of research in the $\mathrm{MN}$ field to date has been focused on the development of various MN platforms and resolving numerous related technical issues rather than exploring clinically relevant applications of MNs. Furthermore, a major limitation of most of the available MN platforms seems to be the dose problem. The amount of vaccine that can be effectively delivered using $\mathrm{MN}$ devices remains fairly low, roughly estimated at approximately $1 \mathrm{mg}$ of dry content for a small $\mathrm{MN}$ array, which in many cases

Table I Vaccines and model antigens used in microneedle-based vaccine delivery trials

\begin{tabular}{|c|c|c|c|c|}
\hline Proteins and inactivated viruses & Virus-like particles & Live viruses & Bacterial antigens & DNA \\
\hline Influenza ${ }^{23,24,26-52}$ & Influenza $22,64-69$ & Adenovirus ${ }^{54,71,72}$ & $\mathrm{BCG}^{76}$ & Hepatitis $B^{84,85}$ \\
\hline Ovalbumin ${ }^{53-57}$ & $\mathrm{HPV}^{70}$ & $\mathrm{MVA}^{72,73}$ & Tetanus $^{32}$ & Hepatitis $\mathrm{C}^{86}$ \\
\hline $\mathrm{BSA}^{58}$ & & Measles $^{74}$ & Diphtheria $^{32,43,77-79}$ & Influenza ${ }^{27,87,88}$ \\
\hline Rotavirus $^{59}$ & & Japanese encephalitis ${ }^{75}$ & Botulism $^{80}$ & $\mathrm{HIV}^{71}$ \\
\hline HIV $^{60}$ & & & Malaria $^{32}$ & Smallpox ${ }^{89}$ \\
\hline Chikungunya virus $^{61}$ & & & Yersinia pestis ${ }^{80,81}$ & Herpes simplex virus ${ }^{90,91}$ \\
\hline Rabies virus ${ }^{62}$ & & & Staphylococcus aureus ${ }^{80}$ & \\
\hline Hepatitis $B^{63}$ & & & Anthrax ${ }^{80,82,83}$ & \\
\hline
\end{tabular}

Abbreviations: BSA, bovine serum albumin; HPV, human papillomavirus; MVA, modified vaccinia virus Ankara; BCG, bacillus Calmette-Guérin; HIV, human immunodeficiency virus. 
is insufficient to accommodate the required human vaccine dose. ${ }^{11,94}$ An obvious way to increase the dosage is to enlarge the MN array. However, increasing the array size brings additional technical challenges, increases production costs, and makes application less convenient. The maximum $\mathrm{MN}$ patch reported to date is a $25 \mathrm{~cm}^{2}$ array, containing approximately 18,000 individual MNs. ${ }^{95}$

The dose problem is likely to be the main technical challenge to be resolved before we see more MN-based vaccines entering clinical phases of development. Therefore, it may be expected that in the short run, development of MN-mediated vaccines will be focused mainly on low-dose and/or selfreplicating vaccines, eg, tuberculosis vaccine or any of the live viral vaccines.

\section{Microneedle platforms for vaccine delivery}

Several diverse MN platforms have been developed to date, which can be divided into four groups based on their basic principle of operation (Figure 1). A great amount of technical skill and engineering ingenuity has been needed for the development of robust fabrication methods for such complex micron-scale devices. Especially challenging is the development of MN-fabrication methods that have the potential to be economically scaled up and installed to pharmaceutical standards. This is still a very lively field of research, with new technologies and approaches emerging frequently. As discussed earlier, there are still a lot of technical issues to be resolved before we see more examples of successful scaling up of laboratory setups to the industrial level and transfer into the clinical stage of development. Recent advances in most promising MN platforms are discussed below.

\section{Solid microneedles}

The simplest form of $\mathrm{MN}$ devices are solid MNs, and most of the early work on MN-assisted delivery of vaccines was done using this type of MN. Solid MNs are usually 70-800 $\mu \mathrm{m}$ long and arranged into one- or two-dimensional arrays, forming an $\mathrm{MN}$ patch. A large number of materials have been tested for fabrication of solid MNs, ranging from silicon and metal to nondegradable polymers and ceramics (for a review, see Kim et $\mathrm{al}^{11}$ ).

Solid MN patches can be used naked for skin pretreatment, and when inserted onto the skin and removed they open pores in the skin surface. Drug or vaccine applied onto treated skin surface diffuses into the skin through pores created by $\mathrm{MN}$ pretreatment. ${ }^{73}$ This approach was used to immunize mice against diphtheria toxoid, giving satisfactory results, and influenza subunit vaccine, with less adequate response. ${ }^{43}$ Better humoral and cellular immune responses against hepatitis B DNA-based vaccine applied topically after skin scraping using solid MNs in comparison with intramuscular or intradermal vaccination by injection were seen in mice. ${ }^{85}$ Recombinant modified vaccinia virus Ankara (MVA) expressing a malaria antigen was administered to mice using a range of silicon $\mathrm{MN}$ patches with different $\mathrm{MN}$ height, density, patch area, and total pore volume. Interestingly, it was found that the design of MN patches significantly influenced



Figure I (A and B) Microneedle (MN)-based platforms for drug and vaccine delivery (reproduced with permission from Kim et al"'). Solid MNs pierce through the outermost layers of the skin, leaving open pores (A) after which drug/vaccine is delivered into the skin (B). Solid MNs may be used for skin pretreatment, after which drug/ vaccine is topically applied and left to diffuse into the skin through opened pores. An alternative way is to precoat the $\mathrm{MN}$ array with a formulation that dissolves off the $\mathrm{MN}$ patch upon contact with the skin (coated MN). Dissolvable MNs contain active ingredient incorporated into water-soluble biodegradable matrix that dissolves on contact with the skin and releases drug/vaccine (dissolving MN). Hollow MNs are used for direct injection of liquid formulation into the skin (hollow MN). 
the magnitude and memory of vaccine-induced $\mathrm{CD} 8^{+} \mathrm{T}$-cell responses and could be optimized for the induction of desired immune responses. Also, unlike administration using hypodermic needles, MN-mediated vaccination did not induce inflammatory responses at the site of immunization or in draining lymph nodes. ${ }^{73}$

The other approach in using solid MNs for vaccine delivery is precoating of $\mathrm{MN}$ patches with water-soluble vaccine formulation before insertion into the skin. After application of such coated MN patches the vaccine is dissolved and released off the patch and into the skin, after which the patch is removed.

Precoating of solid MN arrays with a stable vaccine formulation incorporates drug and delivery device into a single delivery system, thus simplifying application. Techniques for precoating of $\mathrm{MN}$ devices include coating by repeated immersion, ${ }^{96-98}$ simple dip-coating, ${ }^{26,42,98}$ gas-jet dry-coating, ${ }^{99,100}$ coating using aerosolization, ${ }^{101}$ and spraycoating. ${ }^{72,102,103}$

Vaccines coated onto solid MN patches include inactivated influenza ${ }^{26,47,52,100,104}$ and Chikungunya virus vaccines, ${ }^{61}$ virus-like particle-based influenza ${ }^{69}$ and human papillomavirus vaccines, ${ }^{70}$ hepatitis $\mathrm{C},{ }^{86}$ West Nile virus ${ }^{61}$ and herpes simplex virus 2 DNA vaccines, ${ }^{90,91}$ and live MVA and adenoviruses. ${ }^{72}$ In general, results using $\mathrm{MN}$ devices were comparable or superior to those obtained using intradermal or intramuscular routes of application.

Based on the declining proportion of publications describing the use of solid MN vaccine delivery devices in comparison with dissolvable and hollow MN platforms, it seems that these other options may start to dominate the field in upcoming years. However, some solid MN devices for vaccine delivery have shown promising results in the preclinical stage, with clinical trials announced for $2013 .{ }^{47,105,106}$ In addition, most current fabrication methods for dissolvable MNs rely on usage of polydimethylsiloxane molds, which are cast using solid MN arrays. Therefore, although the work on direct use of solid MN arrays for vaccination may be in slow decline, fabrication and design of solid $\mathrm{MN}$ arrays is likely to remain a matter of intensive research.

\section{Hollow microneedles}

Hollow MNs are miniature needles used for direct application of liquid formulation into skin. There are two types of hollow MN designs. One uses a single MN, thus resembling a miniature conventional hypodermic needle. More often, hollow MNs are arranged into arrays, enabling simultaneous application of a vaccine formulation over a wider area of skin.
This may allow not only faster application of the vaccine but higher bioavailability and antigen utilization as well, since a larger application area increases the chances of lymphatic uptake of antigens. ${ }^{107}$

The use of hollow MNs has the great advantage of enabling the use of liquid-vaccine formulations rather than vaccines in a dried form, as required by other MN platforms. Some vaccines cannot be presented in a dried form or may lose activity upon conversion into a dry state, making the use of hollow MNs the preferred choice. On the other hand, hollow MN devices usually require coupling with a syringe or other liquid container and perhaps assistance of trained personnel for application. ${ }^{108}$

To date, an influenza vaccine based on a single hollow MN system has been the most successful commercial application among the vaccine MN-delivery systems. ${ }^{109,110}$ It is, however, debatable whether this system, marketed as BD Soluvia Microinjection System, is an MN or rather a short-needle system, given its $1.5 \mathrm{~mm}$ length compared with other MN devices that are regularly well below $1 \mathrm{~mm}$ in length. ${ }^{111}$ In one study, vaccination using such a single hollow MN device resulted in superior immunogenicity among elderly, which is particularly relevant, as morbidity and mortality from seasonal influenza is the highest in this population. ${ }^{50}$ Also important is the significant dose-sparing effect achieved using the MN device compared with the intramuscular vaccination route. ${ }^{45,49}$ The dose of $15 \mu \mathrm{g}$ of hemagglutinin required for the intramuscular route was reduced to $9 \mu \mathrm{g}$ for the $\mathrm{MN}$ device, giving superior immune response. ${ }^{29,49}$

The potential of using hollow $\mathrm{MN}$ arrays for vaccine delivery was also demonstrated by immunization with ovalbumin and DNA-encoding reporter genes. ${ }^{12}$ Further, few clinically relevant vaccines have been successfully delivered using hollow MN devices in animal models. Vaccines against anthrax ${ }^{83}$ and Japanese encephalitis ${ }^{75}$ were successfully delivered and shown to be safe and efficacious.

\section{Dissolvable microneedles}

Most recently, a very promising approach for MN-mediated vaccine delivery was based on the use of dissolvable $\mathrm{MN}$ arrays. This platform first appeared in 2005, ${ }^{113}$ and has gained significant interest to date. The main idea behind dissolvable $\mathrm{MN}$ platforms is incorporation of vaccine into rigid polymeric or sugar MNs (for a review of fabrication methods, see Kim et $\mathrm{al}^{11}$ ). Upon insertion of dissolvable MNs into the skin, water evaporating from the opened pores dissolves the $\mathrm{MN}$ matrix and releases the vaccine, which then diffuses 
easily into the skin. Materials used in the fabrication of the dissolvable $\mathrm{MN}$ matrix have to be inert, safe, water-soluble, sufficiently hard in dried form, and compatible with vaccine components.

Interest in dissolvable MNs seems to have increased in recent years, driven by the development of a number of dissolvable MN-production methods. These are mostly mold-based techniques, and include various casting, injection-molding, hot-embossing, diffusion-into-mold, spraying-into-mold, and similar techniques. ${ }^{11,114,115}$ Materials tested for suitability in the preparation of dissolvable MNs are indeed numerous. Most of these are various polymers or sugars. Polymers include carboxymethyl cellulose, chondroitin sulfate, polyvinylpyrrolidone, polyvinyl alcohol, poly(lactic-co-glycolic acid), dextran, and dextrin, while the sugars most used are trehalose, maltose, sucrose, and galactose (for reviews, see Prausnitz et $\mathrm{al}^{108}$ and Donnelly et $\mathrm{al}^{111}$ ).

The advantages of dissolvable MNs over other MN platforms are claimed to be cost-effectiveness, biodegradability, robustness, and scalability. ${ }^{111114,116,117}$ Among the disadvantages, two issues may be problematic for certain types of vaccines. One is the already-discussed problem of the dose. The amount of vaccine that can be mixed with matrix components without compromising hardness and rigidity upon drying is fairly limited. Hence, the total amount of vaccine that can be accommodated in an averagesize dissolvable $\mathrm{MN}$ patch is measured on the milligram scale, which may be insufficient for many conventional human vaccines. ${ }^{108}$ The other problem related to incorporation of vaccine into a dry polymer/sugar matrix is stability of active component(s). Traditionally, many vaccines are stabilized in a dry form by freeze-drying. However, unlike structurally very fragile freeze-dried cake, the matrix of dissolvable $\mathrm{MNs}$ has to retain rigidity and hardness to enable penetration into the skin. The properties of such polymer/sugar matrix are very much different from those of freeze-dried forms, and finding a suitable combination of compatible and suitable matrix components may be problematic. Generally, the stability of protein antigens, including inactivated viruses, may be well preserved in certain dissolvable MN platforms, ${ }^{118}$ while the stability of live viruses is likely to be more challenging. ${ }^{114}$

Examples of successful embedding and delivery of vaccines using dissolvable $\mathrm{MN}$ platforms include plasmidencoding hepatitis C antigens, ${ }^{86}$ proteins, ${ }^{53-55,104,119}$ inactivated influenza viruses, ${ }^{53,104,118,120}$ and live adeno- and MVA viruses. ${ }^{114}$ To date, there have been no reports on human trials using dissolvable $\mathrm{MN}$ vaccines. However, given the advantages of dissolvable MNs, in particular industrial scalability and cost of production of dissolvable MN patches, encouraging results of preliminary animal studies, and liveliness in discovery of novel fabrication methods, it is likely that research efforts in this field will bring forth some vaccine products in upcoming years.

\section{Prospects of microneedle-based vaccine delivery technologies}

Research into MN devices is in its fourth decade already. Given the time span and amount of published data, it is somewhat surprising to see the relatively small number of commercial MN-based pharmaceutical products, and MNbased vaccines in particular. The main reason is probably the fact that until recently, fabrication methods for $\mathrm{MN}$ arrays were not mature enough to be the basis of a robust and reproducible industrial process, needed in the pharmaceutical environment. Hence, the interest of the pharmaceutical industry in the research of MN devices was somewhat limited. Recently, however, with the introduction of microelectronic- and laser-based state-of-the-art methods into $\mathrm{MN}$ research, it has become possible to develop production methods that have the potential of scalability and translation of laboratory settings into a good-manufacturing-practice environment. Therefore, it can be expected that enormous efforts invested in design and fabrication methods of $\mathrm{MN}$ devices will finally start giving more clinically relevant results in this decade.

The other important reason that translation of $\mathrm{MN}$-based vaccines into clinical use is still somewhat slow is the sole fact that in most cases, despite all the aforementioned disadvantages, traditional intramuscular or subcutaneous application of a vaccine results in a sufficient and reliable immune protection. The 100-year-long paradigm of needleand syringe-based application of vaccines is simply not easy to put into question. However, the fact that current needle-and-syringe methods work fine may slow down an easy penetration of MN-based alternatives, but with further technological improvements, accumulation of data on efficacy and safety, and paying more attention to the patient's comfort, we are likely to see the introduction of a number of MN-based vaccines by the end of this decade.

To conclude, research on $\mathrm{MN}$ devices for vaccine delivery was until recently more about solving the design and fabrication issues, while now focus is swiftly changing to the use and application of MNs for delivery of clinically relevant vaccines. It is therefore to be expected that vaccination will soon start becoming a needle-free practice. 


\section{Disclosure}

The author reports no conflicts of interest in this work.

\section{References}

1. Saroja C, Lakshmi P, Bhaskaran S. Recent trends in vaccine delivery systems: a review. Int J Pharm Investig. 2011;1(2):64-74.

2. Gomez E, Zoth SC, Berinstein A. Plant-based vaccines for potential human application: a review. Hum Vaccin. 2009;5(11):738-744.

3. Dahlan A, Alpar HO, Stickings P, Sesardic D, Murdan S. Transcutaneous immunisation assisted by low-frequency ultrasound. Int $J$ Pharm. 2009;368(1-2):123-128.

4. Drabick JJ, Glasspool-Malone J, King A, Malone RW. Cutaneous transfection and immune responses to intradermal nucleic acid vaccination are significantly enhanced by in vivo electropermeabilization. Mol Ther. 2001;3(2):249-255.

5. Mohammed AJ, AlAwaidy S, Bawikar S, et al. Fractional doses of inactivated poliovirus vaccine in Oman. $N$ Engl J Med. 2010;362(25): 2351-2359.

6. Dean HJ, Chen D. Epidermal powder immunization against influenza. Vaccine. 2004;23(5):681-686.

7. Guebre-Xabier M, Hammond SA, Epperson DE, Yu J, Ellingsworth L, Glenn GM. Immunostimulant patch containing heat-labile enterotoxin from Escherichia coli enhances immune responses to injected influenza virus vaccine through activation of skin dendritic cells. $J$ Virol. 2003;77(9):5218-5225.

8. Frech SA, Kenney RT, Spyr CA, et al. Improved immune responses to influenza vaccination in the elderly using an immunostimulant patch. Vaccine. 2005;23(7):946-950.

9. Frerichs DM, Ellingsworth LR, Frech SA, et al. Controlled, single-step, stratum corneum disruption as a pretreatment for immunization via a patch. Vaccine. 2008;26(22):2782-2787.

10. Kim YC, Jarrahian C, Zehrung D, Mitragotri S, Prausnitz MR. Delivery systems for intradermal vaccination. Curr Top Microbiol Immunol. 2012;351:77-112.

11. Kim YC, Park JH, Prausnitz MR. Microneedles for drug and vaccine delivery. Adv Drug Deliv Rev. 2012;64(14):1547-1568.

12. Matsuo K, Hirobe S, Okada N, Nakagawa S. Frontiers of transcutaneous vaccination systems: novel technologies and devices for vaccine delivery. Vaccine. 2013;31(19):2403-2415.

13. Kis EE, Winter G, Myschik J. Devices for intradermal vaccination. Vaccine. 2012;30(3):523-538.

14. Gerstel MS, Place VA, inventors. Drug delivery device. United States patent US3964482. June 22, 1976.

15. Kang SM, Song JM, Kim YC. Microneedle and mucosal delivery of influenza vaccines. Expert Rev Vaccines. 2012;11(5):547-560.

16. Hutin YJ, Hauri AM, Armstrong GL. Use of injections in healthcare settings worldwide, 2000: literature review and regional estimates. BMJ. 2003;327(7423):1075.

17. World Health Organization. Safety of injections: global facts and figures. 2004. Available from: http://www.who.int/injection_safety/ about/resources/en/FactAndFiguresInjectionSafety.pdf. Accessed July 17, 2013.

18. Debenedictis C, Joubeh S, Zhang G, Barria M, Ghohestani RF. Immune functions of the skin. Clin Dermatol. 2001;19(5):573-585.

19. KupperTS, Fuhlbrigge RC. Immune surveillance in the skin: mechanisms and clinical consequences. Nat Rev Immunol. 2004;4(3):211-222.

20. Belshe RB, Newman FK, Cannon J, et al. Serum antibody responses after intradermal vaccination against influenza. $N$ Engl J Med. 2004; 351(22):2286-2294.

21. Kenney RT, Frech SA, Muenz LR, Villar CP, Glenn GM. Dose sparing with intradermal injection of influenza vaccine. $N$ Engl J Med. 2004; 351(22):2295-2301.

22. Quan FS, Kim YC, Compans RW, Prausnitz MR, Kang SM. Dose sparing enabled by skin immunization with influenza virus-like particle vaccine using microneedles. J Control Release. 2010;147(3):326-332.
23. Weldon WC, Zarnitsyn VG, Esser ES, et al. Effect of adjuvants on responses to skin immunization by microneedles coated with influenza subunit vaccine. PLoS One. 2012;7(7):e41501.

24. Koutsonanos DG, Vassilieva EV, Stavropoulou A, et al. Delivery of subunit influenza vaccine to skin with microneedles improves immunogenicity and long-lived protection. Sci Rep. 2012;2:357.

25. Wilck MB, Seaman MS, Baden LR, et al. Safety and immunogenicity of modified vaccinia Ankara (ACAM3000): effect of dose and route of administration. J Infect Dis. 2010;201(9):1361-1370.

26. Kim YC, Quan FS, Compans RW, Kang SM, Prausnitz MR. Formulation and coating of microneedles with inactivated influenza virus to improve vaccine stability and immunogenicity. $J$ Control Release. 2010;142(2):187-195.

27. Kim YC, Yoo DG, Compans RW, Kang SM, Prausnitz MR. Cross-protection by co-immunization with influenza hemagglutinin DNA and inactivated virus vaccine using coated microneedles. JControl Release. Epub April 30, 2013

28. Koutsonanos DG, Compans RW, Skountzou I. Targeting the skin for microneedle delivery of influenza vaccine. Adv Exp Med Biol. 2013;785: 121-132.

29. Leroux-Roels I, Weber F. Intanza 9 microg intradermal seasonal influenza vaccine for adults 18 to 59 years of age. Hum Vaccin Immunother. 2013;9(1):115-121.

30. Kommareddy S, Baudner BC, Bonificio A, et al. Influenza subunit vaccine coated microneedle patches elicit comparable immune responses to intramuscular injection in guinea pigs. Vaccine. 2013;31(34): 3435-3441.

31. Choi HJ, Bondy BJ, Yoo DG, Compans RW, Kang SM, Prausnitz MR. Stability of whole inactivated influenza virus vaccine during coating onto metal microneedles. J Control Release. 2013;166(2):159-171.

32. Matsuo K, Hirobe S, Yokota Y, et al. Transcutaneous immunization using a dissolving microneedle array protects against tetanus, diphtheria, malaria, and influenza. J Control Release. 2012;160(3):495-501.

33. del Pilar Martin M, Weldon WC, Zarnitsyn VG, et al. Local response to microneedle-based influenza immunization in the skin. MBio. 2012;3(2): 000012.

34. Choi HJ, Yoo DG, Bondy BJ, et al. Stability of influenza vaccine coated onto microneedles. Biomaterials. 2012;33(14):3756-3769.

35. Kommareddy S, Baudner BC, Oh S, Kwon SY, Singh M, O'Hagan DT. Dissolvable microneedle patches for the delivery of cell-culture-derived influenza vaccine antigens. J Pharm Sci. 2012;101(3):1021-1027.

36. Weldon WC, Martin MP, Zarnitsyn V, et al. Microneedle vaccination with stabilized recombinant influenza virus hemagglutinin induces improved protective immunity. Clin Vaccine Immunol. 2011;18(4): 647-654.

37. Duggan ST, Plosker GL. Intanza 15 microg intradermal seasonal influenza vaccine: in older adults (aged $\geq 60$ years). Drugs Aging. 2010; 27(7):597-605.

38. Kim YC, Quan FS, Compans RW, Kang SM, Prausnitz MR. Stability kinetics of influenza vaccine coated onto microneedles during drying and storage. Pharm Res. 2011;28(1):135-144.

39. Kim YC, Quan FS, Yoo DG, Compans RW, Kang SM, Prausnitz MR. Enhanced memory responses to seasonal H1N1 influenza vaccination of the skin with the use of vaccine-coated microneedles. $J$ Infect Dis. 2010;201(2):190-198.

40. Quan FS, Kim YC, Yoo DG, Compans RW, Prausnitz MR, Kang SM. Stabilization of influenza vaccine enhances protection by microneedle delivery in the mouse skin. PLoS One. 2009;4(9):e7152.

41. Kim YC, Quan FS, Yoo DG, Compans RW, Kang SM, Prausnitz MR. Improved influenza vaccination in the skin using vaccine coated microneedles. Vaccine. 2009;27(49):6932-6938.

42. Zhu Q, Zarnitsyn VG, Ye L, et al. Immunization by vaccine-coated microneedle arrays protects against lethal influenza virus challenge. Proc Natl Acad Sci U S A. 2009;106(19):7968-7973.

43. Ding Z, Verbaan FJ, Bivas-Benita M, et al. Microneedle arrays for the transcutaneous immunization of diphtheria and influenza in BALB/c mice. J Control Release. 2009;136(1):71-78. 
44. Koutsonanos DG, del Pilar Martin M, Zarnitsyn VG, et al. Transdermal influenza immunization with vaccine-coated microneedle arrays. PLoS One. 2009;4(3):e4773.

45. Van Damme P, Oosterhuis-Kafeja F, Van der Wielen M, Almagor Y, Sharon O, Levin Y. Safety and efficacy of a novel microneedle device for dose sparing intradermal influenza vaccination in healthy adults. Vaccine. 2009;27(3):454-459.

46. Alarcon JB, Hartley AW, Harvey NG, Mikszta JA. Preclinical evaluation of microneedle technology for intradermal delivery of influenza vaccines. Clin Vaccine Immunol. 2007;14(4):375-381.

47. Fernando GJ, Chen X, Prow TW, et al. Potent immunity to low doses of influenza vaccine by probabilistic guided micro-targeted skin delivery in a mouse model. PLoS One. 2010;5(4):e10266.

48. Beran J, Ambrozaitis A, Laiskonis A, et al. Intradermal influenza vaccination of healthy adults using a new microinjection system: a 3-year randomised controlled safety and immunogenicity trial. BMC Med. 2009;7:13

49. Leroux-Roels I, Vets E, Freese R, et al. Seasonal influenza vaccine delivered by intradermal microinjection: a randomised controlled safety and immunogenicity trial in adults. Vaccine. 2008;26(51):6614-6619.

50. Holland D, Booy R, De Looze F, et al. Intradermal influenza vaccine administered using a new microinjection system produces superior immunogenicity in elderly adults: a randomized controlled trial. $J$ Infect Dis. 2008;198(5):650-658.

51. Arnou R, Icardi G, De Decker M, et al. Intradermal influenza vaccine for older adults: a randomized controlled multicenter phase III study. Vaccine. 2009;27(52):7304-7312.

52. Fernando GJ, Chen X, Primiero CA, et al. Nanopatch targeted delivery of both antigen and adjuvant to skin synergistically drives enhanced antibody responses. J Control Release. 2012;159(2):215-221.

53. Guo L, Chen J, Qiu Y, Zhang S, Xu B, Gao Y. Enhanced transcutaneous immunization via dissolving microneedle array loaded with liposome encapsulated antigen and adjuvant. Int J Pharm. 2013; 447(1-2):22-30

54. Matsuo K, Yokota Y, Zhai Y, et al. A low-invasive and effective transcutaneous immunization system using a novel dissolving microneedle array for soluble and particulate antigens. J Control Release. 2012; 161(1):10-17.

55. Naito S, Ito Y, Kiyohara T, Kataoka M, Ochiai M, Takada K. Antigen-loaded dissolving microneedle array as a novel tool for percutaneous vaccination. Vaccine. 2012;30(6):1191-1197.

56. Bal SM, Slutter B, Jiskoot W, Bouwstra JA. Small is beautiful: N-trimethyl chitosan-ovalbumin conjugates for microneedle-based transcutaneous immunisation. Vaccine. 2011;29(23):4025-4032.

57. Widera G, Johnson J, Kim L, et al. Effect of delivery parameters on immunization to ovalbumin following intracutaneous administration by a coated microneedle array patch system. Vaccine. 2006;24(10): $1653-1664$.

58. Kochhar JS, Zou S, Chan SY, Kang L. Protein encapsulation in polymeric microneedles by photolithography. Int J Nanomedicine. 2012;7: 3143-3154.

59. Moon S, Wang Y, Edens C, Gentsch JR, Prausnitz MR, Jiang B. Dose sparing and enhanced immunogenicity of inactivated rotavirus vaccine administered by skin vaccination using a microneedle patch. Vaccine. 2013; 31(34): 3396-3402.

60. Pattani A, McKay PF, Garland MJ, et al. Microneedle mediated intradermal delivery of adjuvanted recombinant HIV-1 CN54 gp140 effectively primes mucosal boost inoculations. J Control Release. 2012;162(3):529-537.

61. Prow TW, Chen X, Prow NA, et al. Nanopatch-targeted skin vaccination against West Nile virus and Chikungunya virus in mice. Small. 2010; 6(16):1776-1784.

62. Laurent PE, Bourhy H, Fantino M, Alchas P, Mikszta JA. Safety and efficacy of novel dermal and epidermal microneedle delivery systems for rabies vaccination in healthy adults. Vaccine. 2010;28(36): 5850-5856.

63. AndrianovAK, DeCollibus DP, Gillis HA, etal. Poly[di(carboxylatophenoxy) phosphazene] is a potent adjuvant for intradermal immunization. Proc Natl Acad Sci U S A. 2009;106(45):18936-18941.
64. Pearton M, Pirri D, Kang SM, Compans RW, Birchall JC. Host responses in human skin after conventional intradermal injection or microneedle administration of virus-like-particle influenza vaccine. Adv Healthc Mater. Epub April 8, 2013.

65. Song JM, Kim YC, Barlow PG, et al. Improved protection against avian influenza $\mathrm{H} 5 \mathrm{~N} 1$ virus by a single vaccination with virus-like particles in skin using microneedles. Antiviral Res. 2010;88(2):244-247.

66. Pearton M, Kang SM, Song JM, et al. Influenza virus-like particles coated onto microneedles can elicit stimulatory effects on Langerhans cells in human skin. Vaccine. 2010;28(37):6104-6113.

67. Kim YC, Quan FS, Compans RW, Kang SM, Prausnitz MR. Formulation of microneedles coated with influenza virus-like particle vaccine. AAPS Pharm Sci Tech. 2010;11(3):1193-1201.

68. Song JM, Kim YC, Lipatov AS, et al. Microneedle delivery of $\mathrm{H} 5 \mathrm{~N} 1$ influenza virus-like particles to the skin induces long-lasting B- and T-cell responses in mice. Clin Vaccine Immunol. 2010;17(9): 1381-1389.

69. Quan FS, Kim YC, Vunnava A, et al. Intradermal vaccination with influenza virus-like particles by using microneedles induces protection superior to that with intramuscular immunization. $J$ Virol. 2010;84(15):7760-7769.

70. Corbett HJ, Fernando GJ, Chen X, Frazer IH, Kendall MA. Skin vaccination against cervical cancer associated human papillomavirus with a novel micro-projection array in a mouse model. PLoS One. 2010;5(10):e13460.

71. Bachy V, Hervouet C, Becker PD, et al. Langerin negative dendritic cells promote potent $\mathrm{CD} 8+\mathrm{T}$-cell priming by skin delivery of live adenovirus vaccine microneedle arrays. Proc Natl Acad Sci U S A. 2013;110(8): 3041-3046.

72. Vrdoljak A, McGrath MG, Carey JB, et al. Coated microneedle arrays for transcutaneous delivery of live virus vaccines. J Control Release. 2012;159(1):34-42.

73. Carey JB, Pearson FE, Vrdoljak A, et al. Microneedle array design determines the induction of protective memory CD8+ T cell responses induced by a recombinant live malaria vaccine in mice. PLoS One. 2011;6(7):e22442.

74. Edens C, Collins ML, Ayers J, Rota PA, Prausnitz MR. Measles vaccination using a microneedle patch. Vaccine. 2013; 31(34):3403-3409.

75. Dean $\mathrm{CH}$, Alarcon JB, Waterston AM, et al. Cutaneous delivery of a live, attenuated chimeric flavivirus vaccine against Japanese encephalitis (ChimeriVax)-JE) in non-human primates. Hum Vaccin. 2005;1(3):106-111.

76. Hiraishi Y, Nandakumar S, Choi SO, et al. Bacillus Calmette-Guerin vaccination using a microneedle patch. Vaccine. 2011;29(14): 2626-2636.

77. Bal SM, Ding Z, Kersten GF, Jiskoot W, Bouwstra JA. Microneedlebased transcutaneous immunisation in mice with $\mathrm{N}$-trimethyl chitosan adjuvanted diphtheria toxoid formulations. Pharm Res. 2010;27(9):1837-1847.

78. Ding Z, Bal SM, Romeijn S, Kersten GF, Jiskoot W, Bouwstra JA. Transcutaneous immunization studies in mice using diphtheria toxoidloaded vesicle formulations and a microneedle array. Pharm Res. 2011;28(1):145-158.

79. Ding Z, Van Riet E, Romeijn S, Kersten GF, Jiskoot W, Bouwstra JA. Immune modulation by adjuvants combined with diphtheria toxoid administered topically in BALB/c mice after microneedle array pretreatment. Pharm Res. 2009;26(7):1635-1643.

80. Morefield GL, Tammariello RF, Purcell BK, et al. An alternative approach to combination vaccines: intradermal administration of isolated components for control of anthrax, botulism, plague and staphylococcal toxic shock. J Immune Based Ther Vaccines. 2008;6:5.

81. Huang J, D’Souza AJ, Alarcon JB, et al. Protective immunity in mice achieved with dry powder formulation and alternative delivery of plague F1-V vaccine. Clin Vaccine Immunol. 2009;16(5):719-725.

82. Mikszta JA, Dekker JP III, Harvey NG, et al. Microneedle-based intradermal delivery of the anthrax recombinant protective antigen vaccine. Infect Immun. 2006;74(12):6806-6810. 
83. Mikszta JA, Sullivan VJ, Dean C, et al. Protective immunization against inhalational anthrax: a comparison of minimally invasive delivery platforms. J Infect Dis. 2005;191(2):278-288.

84. Yin D, Liang W, Xing S, et al. Hepatitis B DNA vaccine-polycation nano-complexes enhancing immune response by percutaneous administration with microneedle. Biol Pharm Bull. Epub May 15, 2013.

85. Mikszta JA, Alarcon JB, Brittingham JM, Sutter DE, Pettis RJ, Harvey NG. Improved genetic immunization via micromechanical disruption of skin-barrier function and targeted epidermal delivery. Nat Med. 2002;8(4):415-419.

86. Gill HS, Soderholm J, Prausnitz MR, Sallberg M. Cutaneous vaccination using microneedles coated with hepatitis C DNA vaccine. Gene Ther. 2010;17(6):811-814.

87. Song JM, Kim YC, O EJ, Compans RW, Prausnitz MR, Kang SM. DNA vaccination in the skin using microneedles improves protection against influenza. Mol Ther. 2012;20(7):1472-1480.

88. Kim YC, Song JM, Lipatov AS, et al. Increased immunogenicity of avian influenza DNA vaccine delivered to the skin using a microneedle patch. Eur J Pharm Biopharm. 2012;81(2):239-247.

89. Hooper JW, Golden JW, Ferro AM, King AD. Smallpox DNA vaccine delivered by novel skin electroporation device protects mice against intranasal poxvirus challenge. Vaccine. 2007;25(10):1814-1823.

90. Chen X, Kask AS, Crichton ML, et al. Improved DNA vaccination by skin-targeted delivery using dry-coated densely-packed microprojection arrays. J Control Release. 2010;148(3):327-333.

91. Kask AS, Chen X, Marshak JO, et al. DNA vaccine delivery by densely-packed and short microprojection arrays to skin protects against vaginal HSV-2 challenge. Vaccine. 2010;28(47): 7483-7491.

92. Alving CR. Design and selection of vaccine adjuvants: animal models and human trials. Vaccine. 2002;20 Suppl 3:S56-S64.

93. Brennan FR, Dougan G. Non-clinical safety evaluation of novel vaccines and adjuvants: new products, new strategies. Vaccine. 2005; 23(24):3210-3222.

94. Gill HS, Prausnitz MR. Coating formulations for microneedles. Pharm Res. 2007;24(7):1369-1380.

95. Donnelly RF, Singh TR, Garland MJ, et al. Hydrogel-forming microneedle arrays for enhanced transdermal drug delivery. Adv Funct Mater. 2012;22(23):4879-4890.

96. Maa YF, Matriano J, Ramdas A, Sellers S, inventors. Apparatus and method for transdermal delivery of influenza vaccine. World Intellectual Property Organization patent WO2005099751A3. September 27, 2005.

97. Matriano JA, Cormier M, Johnson J, et al. Macroflux microprojection array patch technology: a new and efficient approach for intracutaneous immunization. Pharm Res. 2002;19(1):63-70.

98. Gill HS, Prausnitz MR. Coated microneedles for transdermal delivery. $J$ Control Release. 2007;117(2):227-237.

99. Chen X, Prow TW, Crichton ML, et al. Dry-coated microprojection array patches for targeted delivery of immunotherapeutics to the skin. J Control Release. 2009;139(3):212-220.

100. Chen X, Fernando GJ, Crichton ML, et al. Improving the reach of vaccines to low-resource regions, with a needle-free vaccine delivery device and long-term thermostabilization. J Control Release. 2011;152(3):349-355.

101. Cormier M, Johnson B, Ameri M, et al. Transdermal delivery of desmopressin using a coated microneedle array patch system. J Control Release. 2004;97(3):503-511.

102. McGrath MG, Vrdoljak A, O’Mahony C, Oliveira JC, Moore AC, Crean AM. Determination of parameters for successful spray coating of silicon microneedle arrays. Int J Pharm. 2011;415(1-2):140-149.
103. Crean A, McGrath M, Moore AC, Vrdoljak A, O’Mahony C, inventors. Dissolvable array and spray coating method. UK patent application GB1019577.4. Nov 2010.

104. Raphael AP, Prow TW, Crichton ML, Chen X, Fernando GJ, Kendall MA. Targeted, needle-free vaccinations in skin using multilayered, densely-packed dissolving microprojection arrays. Small. 2010;6(16):1785-1793.

105. Ng HI, Fernando GJ, Kendall MA. Induction of potent CD8(+) T cell responses through the delivery of subunit protein vaccines to skin antigen-presenting cells using densely packed microprojection arrays. $J$ Control Release. 2012;162(3):477-484.

106. Malhotra R. Trials planned for pain-free, low-cost vaccine delivery. 2013. Available from: http://www.scidev.net/en/new-technologies/ nanotechnology/news/trials-planned-for-pain-free-low-cost-vaccinedelivery.html. Accessed June 6, 2013.

107. Harvey AJ, Kaestner SA, Sutter DE, Harvey NG, Mikszta JA, Pettis RJ. Microneedle-based intradermal delivery enables rapid lymphatic uptake and distribution of protein drugs. Pharm Res. 2011; 28(1):107-116.

108. Prausnitz MR, Mikszta JA, Cormier M, Andrianov AK. Microneedlebased vaccines. Curr Top Microbiol Immunol. 2009;333:369-393.

109. Eizenberg P, Booy R, Naser N, Mason G, Stamboulian D, Weber F. Acceptance of Intanza $9 \mu \mathrm{g}$ intradermal influenza vaccine in routine clinical practice in Australia and Argentina. Adv Ther. 2011;28(8): 640-649.

110. Atmar RL, Patel SM, Keitel WA. Intanza: a new intradermal vaccine for seasonal influenza. Expert Rev Vaccines. 2010;9(12): 1399-1409.

111. Donnelly RF, Raj Singh TR, Woolfson AD. Microneedle-based drug delivery systems: microfabrication, drug delivery, and safety. Drug Deliv. 2010;17(4):187-207.

112. Daugimont L, Baron N, Vandermeulen G, et al. Hollow microneedle arrays for intradermal drug delivery and DNA electroporation. J Membr Biol. 2010;236(1):117-125.

113. Park JH, Allen MG, Prausnitz MR. Biodegradable polymer microneedles: fabrication, mechanics and transdermal drug delivery. J Control Release. 2005;104(1):51-66.

114. Moore AC, Vrdoljak A, inventors. Method for fabricating a microneedle, and produced microneedle. World Intellectual Property Organization patent WO2012153266A2. 2012.

115. Carey JB, Crean A, McGrath M, O’Mahony C, Moore AC, Vrdoljak A, inventors. Method for fabricating a microneedle. World Intellectual Property Organization patent. WO2012066506A2. May 24, 2012.

116. Lee JW, Park JH, Prausnitz MR. Dissolving microneedles for transdermal drug delivery. Biomaterials. 2008;29(13):2113-2124.

117. McGrath MG, Vucen S, Vrdoljak A, et al. Production of dissolvable microneedles using an atomized spray process: effect of microneedle composition on skin penetration. Eur J Pharm Biopharm. Epub May 29, 2013.

118. Demuth PC, Garcia-Beltran WF, Ai-Ling ML, Hammond PT, Irvine DJ. Composite dissolving microneedles for coordinated control of antigen and adjuvant delivery kinetics in transcutaneous vaccination. Adv Funct Mater. 2013;23(2):161-172.

119. Ikejiri A, Ito Y, Naito S, Takada K. Two-and three-layered dissolving microneedles for transcutaneous delivery of model vaccine antigen in rats. J Biomater Nanobiotechnol. 2012;3:325-334.

120. Sullivan SP, Koutsonanos DG, del Pilar Martin M, et al. Dissolving polymer microneedle patches for influenza vaccination. Nat Med. 2010;16(8):915-920. 


\section{Publish your work in this journal}

Vaccine: Development and Therapy is an international, peer-reviewed, open access journal that spans the spectrum of vaccine design and development through to clinical applications. The journal is characterized by the rapid reporting of application notes, reviews, original research and clinical studies in all therapeutic areas. Clinical outcomes, patient safety, and programs for the development and effective, safe, and sustained use of vaccines will be a feature of the journal. The manuscript management system is completely online and includes a very quick and fair peer-review system. Visit http://www.dovepress.com/testimonials.php to read real quotes from published authors. 